\title{
KENDALI MOBIL ROBOT MENGGUNAKAN ISYARAT TANGAN BERBASIS ARDUINO
}

\author{
Jati Widyo Leksono ${ }^{1)}$, Agung Samudra ${ }^{2}$, Nanndo Yannuansa ${ }^{3)}$, dan Ahmad Fauzi ${ }^{4)}$ \\ ${ }^{1}$ Teknik Elektro, Universitas Hasyim Asy'ari Tebuireng Jombang \\ ${ }^{2}$ Teknik Mesin, Univeristas Hasyim Asy'ari Tebuireng Jombang \\ ${ }^{3}$ Teknik Elektro, Univeristas Hasyim Asy'ari Tebuireng Jombang \\ ${ }^{4}$ Teknik Elektro, Univeristas Hasyim Asy'ari Tebuireng Jombang \\ 1jatiwidyoleksono@gmail.com, ${ }^{2}$ agung@gmail.com, ${ }^{3}$ nanndo@gmail.com, ${ }^{4}$ fauzi @gmail.com
}

\begin{abstract}
Abstrak
Perkembangan teknologi mobil robot dari tahun ke tahun terus mengalami tingkat kemajuan yang pesat. Di era awal teknologi robotika, pergerakan suatu robot tidak dapat dikontrol manusia dari jarak yang jauh. Saat ini robot tidak lagi dikontrol dengan menggunakan remote kontrol, namun bisa menggunakan perintah dari manusia secara langsung. Dalam penelitian ini dilakukan pengembangan mobil robot mampu berjalan sesuai dengan isyarat tangan atau gestur tangan. Di telapak tangan manusia ditempelkan suatu sensor yang mampu membaca pergerakkan arah atas, bawah, samping kiri maupun samping kanan. Dari pembacaan sensor gestur tangan tersebut, modul tersebut mengirimkan data menuju receiver yang terdapat di dalam robot secara wireless. Selanjutnya, robot tersebut akan menerima data input kendali perintah logika pemograman untuk menentukan aksi berupa gerakan arah robot. Mobil robot tersebut akan bergerak maju, mundur, berbelok kanan, berbelok kiri, maupun berhenti. Kendali isyarat tangan yang digunakan tersebut menggunakan modul sensor MPU-6050 yang ditransmisikan melalui gelombang frekuensi radio NRF24L01. Berdasarkan hasil pengujian, modul sensor tesebut mampu membaca posisi titik sumbu $\mathrm{x}, \mathrm{y}$, dan z dengan baik. Hasil kecepatan respon sensor terhadap mobil robot mampu terhubung cepat hanya dengan kisaran waktu selama $0,45 \mathrm{~s}$. Selain itu, pengujian rata-rata kecepatan mobil robot tersebut mampu melaju sebesar 3.496,50 rpm sampai dengan 4.596,50 rpm.
\end{abstract}

\section{Kata kunci : Robot, Gesture Tangan, Mobil Robot}

\begin{abstract}
The development of technology robot car from year to year, it turned out continue to experienced the level of rapid progress. Current robots are no longer controlled by using the remote control, but can use command from the man directly. In this research, the development of a robot car capable of running in accordance with a hand gesture or hand gesture.

In the palm of human hand affixed to a sensor that is able to read movement direction of top, bottom, left side and right side. Sensor readings from the gesture of the hand, module sends data to the receiver that are contained in the robot wirelessly. Robot will receive data input control command logic programming to specify the action. The robot will move forward, backward, turn right, turn left, stop. Control hand gesture that is using the sensor module MPU-6050 are transmitted through radio frequency waves NRF24L01. Based on the results of testing, module proficiency level sensor capable of reading the position of a point of the axis $\mathrm{x}, \mathrm{y}$, and $\mathrm{z}$. The results of response speed of sensor against car is able to connect quickly $0.45 \mathrm{~s}$. Testing the average speed of car robot is capable of driving amounted to $3.496,50 \mathrm{rpm}$ up to $4.596,50 \mathrm{rpm}$.
\end{abstract}

\section{Keywords: Robotic, Hand Gesture Control, Electric Car Robot}




\section{PENDAHULUAN}

Dalam upaya peningkatan kemandirian bangsa di dunia industri, perguruan tinggi dituntut untuk dapat berinovasi menghasilkan suatu karya anak bangsa yang dapat digunakan untuk banyak kalangan. Salah satunya adalah robotika. Robotika merupakan perpaduan berbagai mikrokontroller yang dirangkai sedemikian sehingga dapat bekerja sesuai yang diinginkan. Bahkan, robotika saat ini mampu bekerja dengan kendali atau kontrol secara jarak jauh.

Perkembangan teknologi kendali robot saat berkembang secara pesat. Dahulunya, kontrol robot harus dikendalikan dengan jarak yang sangat dekat. Beberapa tahun kemudian, robot sudah biasa dikendalikan dengan jarak jauh dengan mennggunakan joystick atau remote kontrol dengan media kabel. Perkembangan selanjutnya sistem kendali itu dapat digunakan tanpa menggunakan kabel atau wireless. Pada akhirnya saat ini dikembangkan teknologi kendali robot yang dapat langsung bekerja dengan menggunakan gestur tangan manusia.

Gestur merupakan salah satu bentuk komunikasi non-verbal manusia yang dilakukan dengan menggerakkan anggota tubuhnya bertujuan untuk menyampaikan pesan-pesan tertentu. Hal itu dilakukan sebagai pengganti seseorang yang berbicara secara langsung. Gestur seseorang meliputi pergerakan dari tangan, wajah, atau bagian lain dari tubuh. Pergerakkan tangan ini digolongkan dalam bentuk pesan non verbal yang dituangkan dalam bentuk bahasa isyarat tubuh atau anggota tubuh (kinesika). Di dalam kajian studi kinesik oleh Ray Birdwhistel, yang menggunakan linguistik sebagai model bagi studi kinesik. Menurutnya suatu gestur tangan adalah bagian tubuh manusia yang paling sering digunakan untuk mengekspresikan suatu emosi. Emosi manusia ketika berbahagia dengan berjabat tangan maupun di saat manusia tidak senang dengan menggerakkan tangannya ke bagian-bagian tertentu.

Selain berbicara secara langsung, kecenderungan gestur manusia lebih sering berkomunikasi yaitu dengan pergerakkan tangan. Dengan menggerakkan tangan ini, tentu kita lebih mudah melakukan komunikasi karena lebih interaktif secara alami dan proses menggerakkannya yang relatif lebih singkat.

Dengan berkembangannya ilmu pengetahuan saat ini, gestur tangan manusia memang dianggap sesuai dalam pengembangan bentuk kendali atau kontol suatu robot. Nantinya, robot tersebut dapat bekerja dengan hanya menggerakkan tangannya. Di telapak tangan manusia ditempelkan suatu sensor yang mampu membaca pergerakkan arah atas, bawah, samping kiri maupun samping kanan.

Dari pembacaan sensor gestur tangan tersebut, modul tersebut mengirimkan data menuju receiver yang terdapat di dalam robot secara wireless. Selanjutnya, robot tersebut akan menerima data input kendali perintah logika pemograman untuk menentukan aksi berupa gerakan arah robot.

\section{METODOLOGI}

\subsection{Alur Sistem Kerja}

Perancangan sistem yang dilakukan melalui beberapa langkah yang meliputi: (1) penyusunan tahap kerja penelitian salah satunya melakukan perumusan masalahan dan menyusun hipotesa. Kemudian, melakukan kajian pustaka sebagai landasan teori yang diperlukan untuk mengkaji segala pemecahan masalah yang terdapat di dalam proses sistem kendali. ; (2) Tahap berikutnya melakukan rancang bangun di dalam perangkat keras (hardware) dan perangkat lunak (software). Pada perancangan software terdiri atas perancangan algoritma program pengenalan gestur tangan dan algoritma navigasi pergerakan mobil robot menggunakan Arduino IDE (Platform aplikasi yang berfungsi sebagai tempat penulisan rangkaian fungsi-fungsi dari bahasa pemograman $\mathrm{C}$ dan bahasa $\mathrm{C}++$ ). Sedangkan di dalam perancangan hardware terdiri atas sebuah prototype mobil robot, 
dan sistem navigasi dengan media transmisi berupa gelombang frekuensi. ; (3) Tahap berikutnya adalah dengan melakukan pengujian software pengenalan gestur tangan dan navigasi dimulai dari proses akuisisi.; (4) Tahap selanjutnya melakukan suatu proses integrasi software dan hardware, melakukan pengambilan data untuk proses pengujian, validasi dan analisa dari percobaan yang telah dilakukan. (5) Tahap yang terakhir adalah menarik kesimpulan dari kinerja transmisi motor yang telah dilakukan.

Gambaran alur sistem kerja dari mobil robot beroda ini melalui beberapa tahap. Pertamatahap deteksi koordinat jari dan tangan yang digerakkan oleh pengguna sehingga akan merespon sensor untuk memberikan perintah kepada penerima di jaringan sistem mobil yang digambarkan pada alur Gambar 1 di bawah ini:

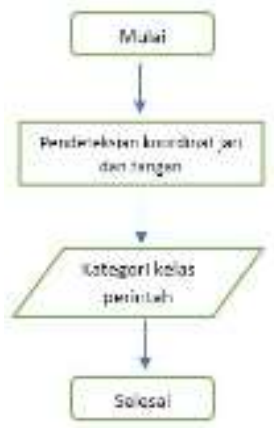

Gambar 1. Diagram Alur Pertama

Tahap alur berikutnya dilanjutkan dari kategori kelas perintah yang telah terbaca itu dikirimkan ke receiver mobil melalui gelombang frekuensi radio. Gambar 2. menunjukkan proses alur lanjutan yang mengarah kendali mobil bergerak ke arah maju, mundur, ke kanan, kiri maupun harus berhenti.

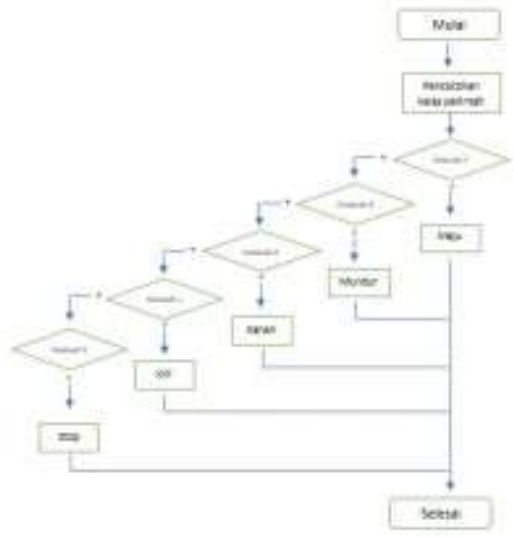

Gambar 2. Diagram Alur Kedua

Perancangan data bentuk pergerakan tangan disimpan dalam mikrokontroller. Ketika input gestur tangan bergerak, mikrokontroller melakukan pencocokan dengan database yang ada. Kemudian intruksi tersebut dikirim ke mobil robot melalui gelombang radio.

\subsection{Pengenalan Gestur Tangan}

Bentuk-bentuk pola gestur tangan yang digunakan berupa pergerakan telapak tangan yang akan menjadi suatu instruksi navigasi pada kontrol mobil robot.

Di dalam menentukan koordinat isyarat tangan yang diletakkan di telapak seseorang, diperlukan pola yang terdapat sumbu bidang x,y,z seperti pada Gambar 3. di bawah ini: 


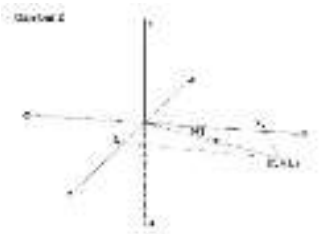

Gambar 3. Sumbu Bidang $\mathrm{x}$, y dan z

Kode instruksi pemrograman yang telah diatur dari komputer disimpan di dalam mikrokontroler. Ketika mulai dilakukan suatu pergerakan dari sensor pada tangan, mikrokontroler mengirimkan instruksi melalui gelombang frekuensi menuju driver motor untuk menggerakkan mobil robot sesuai dengan instruksi yang diberikan.

Di dalam menentukan koordinat isyarat tangan yang diletakkan di telapak seseorang, diperlukan pola persamaan antara sudut dan jarak yang yaitu sebagai berikut:

$$
d(x y z)=\sqrt{\left(x_{2}-x_{1}\right)^{2}+\left(y_{2}-y_{1}\right)^{2}+\left(z_{2}-z_{1}\right)^{2}}
$$

Keterangan :

$$
\begin{array}{ll}
\mathrm{d}(\mathrm{xyz}) & =\text { jarak ruang tiga bidang } \mathrm{x}, \mathrm{y}, \text { dan } \mathrm{z} . \\
\mathrm{x} & =\text { nilai } \mathrm{x} \text { pada bidang ruang. } \\
\mathrm{y} & =\text { nilai y pada bidang ruang. } \\
\mathrm{z} & =\text { nilai } \mathrm{z} \text { pada bidang ruang. }
\end{array}
$$

\section{PEMBAHASAN}

Sistem kendali mobil robot beroda menggunakan masukan (input) data yang berasal dari gestur tangan yang digerakkan. Hal ini membutuhkan suatu sensor gesture yang bernama MPU-6050.

\subsection{Skema Rangkaian}

Kemampuan dari sensor MPU-6050 ini dapat bekerja secara akurat dalam mengkonversi data - data analog menjadi digital. Sensor ini juga memiliki resolusi 16-bit pada di setiap chanelnya.[4]

Oleh karena itu, modul sensor ini dapat membaca data dari chanel sumbu $\mathrm{x}, \mathrm{y}$, dan $\mathrm{z}$ secara bersamaan dalam satu waktu. Kelebihan lainnya, sensor MPU-6050 ini menggunakan komunikasi I2C.[5] Suatu koneksi komunikasi yang hanya memerlukan 2 kabel data SDA dan SCL serta 2 kabel daya power seperti pada Gambar 4. di bawah ini:

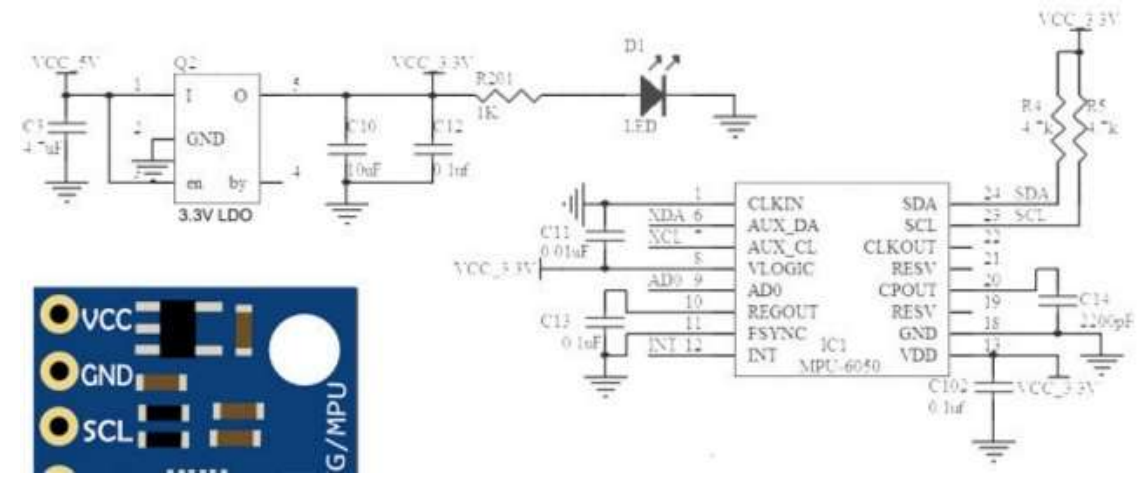

Gambar 4. Skematik Rangkaian MPU-6050

Modul sensor MPU-6050 pada Gambar 4. merupakan mikrokontroller berperan sebagai sensor Accelerometer dan Gyroscope.[6] Sensor ini berkerja membaca posisi koordinat pada suatu bidang $\mathrm{x}, \mathrm{y}$, dan z sesuai Gambar 5 berikut ini: 


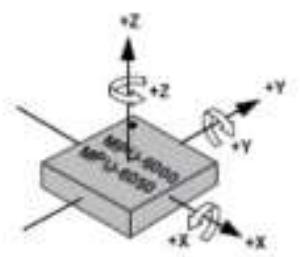

Gambar 5. Kinerja Arah MPU-6050

Sensor Accelerometer yang terdapat pada sensor ini berfungsi untuk mengetahui suatu percepatan gravitasi, sedangkan gyroscope berfungsi untuk mengetahui kecepatan sudut.[7] Dengan demikian, kedua sensor akan menghasilkan output berupa orientasi seperti Gambar 6. di bawah ini:

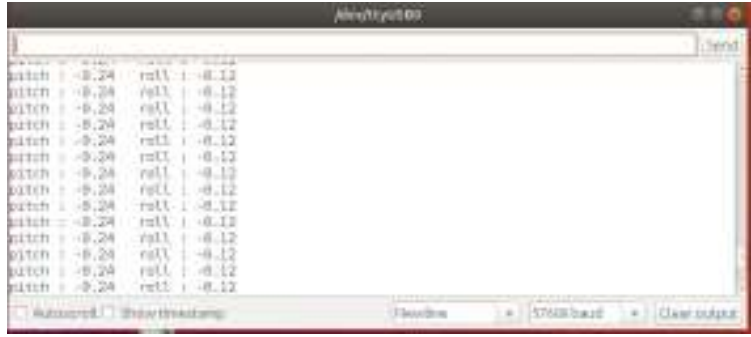

Gambar 6. Hasil Output Orientasi Sensor MPU-6050 berupa Pitch dan Roll

Nilai orientasi yang telah didapatkan akan menjadi acuan input berikutnya dalam memberikan perintah atau instruksi yang diatur dalam bahasa pemprograman.[8] Adapun bentuk pola gestur tangan yang diatur dapat dilihat pada Tabel 1 di bawah ini:

Tabel 1. Bentuk Pola Gestur Tangan

\begin{tabular}{|c|c|c|}
\hline Gestur Telapak & Intruksi & Kode Instruksi \\
\hline Menurun & Maju & $\mathrm{F}$ \\
\hline Dinaikkan & Mundur & $\mathrm{B}$ \\
\hline Kiri & Kiri & L \\
\hline Kanan & Kanan & R \\
\hline Mendatar & Berhenti & S \\
\hline
\end{tabular}

Dari instruksi telapak tangan yang dirancang pada Tabel 1. di atas, mulai dilakukan pembuatan kode instruksi yang dituliskan pada program aplikasi arduino IDE berupa maju (F), mundur (B), kiri (L), kanan (R) dan berhenti (S).

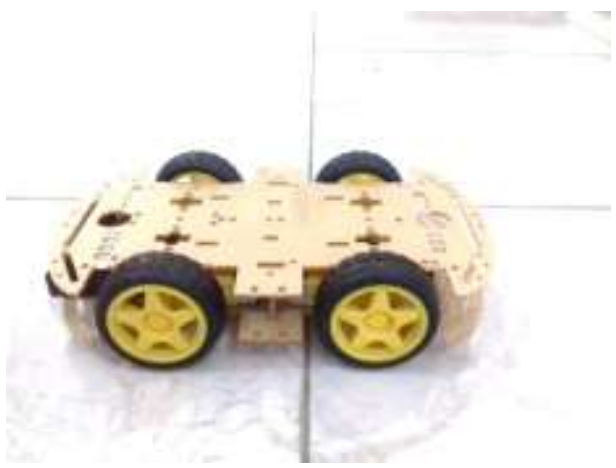

Gambar 7. Mobil Robot Beroda 
Setelah dilakukan pengaturan posisi gestur sensor tangan, pembuatan mobil dapat dilakukan dengan baik. Mobil robot yang terbentuk seperti pada Gambar 7. di atas. Pada bagian mobil robot ini terdapat beberapa komponen elektronik yang terpasang, diantaranya sebuatu mikrokontroller Arduino uno dan mikrokontroller Arduino nano , 2 buah .FC-03, L298N motor driver dual, modul charger Tp 4056, baterai Lithium 18650, 2 buah buck converter yang dilengkapi soket adaptor NRF24L01 sebagai penstabil tegangan. Komponen mekanik terdapat 4 buah roda, 4 buah gearbox motor, 2 buah chassis dihubungkan dengan antena gelombang radio NRF24L01.

\subsection{Hasil Pengujian}

Remote kendali ini akan dibuat dengan suatu teknologi leap motion. Leap motion berfungsi untuk mendeteksi posisi titik-titik koordinat (x, y dan z).

Data koordinat tersebut akan digunakan untuk membentuk fitur. Fitur yang telah dibentuk akan diambil nilai rata-ratanya. Nilai rata-rata fitur tersebut akan dijadikan sebagai nilai untuk menentukan range atau area, dimana ada 5 range atau area (nilai range forward, backward, stop, right dan left). Setiap nilai uji coba akan dicocokkan dengan nilai range yang ada untuk menjalankan robot beroda. Sistem ini diharapkan dapat mengontrol robot beroda dengan instruksi maju, mundur, berhenti, belok kanan, dan belok kiri. Adapun untuk mengukur keberhasilan dari sistem ini akan dilakukan uji coba dengan mengukur tingkat akurasinya seperti yang terlihat pada Tabel 2. di bawah ini:

Tabel 2. Hasil Uji Akurasi Gestur - Mobil Robot

\begin{tabular}{|c|c|c|}
\hline Gestur Telapak & Intruksi & Persentase (\%) \\
\hline Menurun & Maju & 100 \\
\hline Dinaikkan & Mundur & 100 \\
\hline Kiri & Kiri & 100 \\
\hline Kanan & Kanan & 100 \\
\hline Mendatar & Berhenti & 100 \\
\hline
\end{tabular}

Pada Tabel 2. menunjukkan bahwa respon mikrotroller dengan pergerakkan sensor tangan dapat bekerja dengan baik secara $100 \%$.

Konfigurasi yang telah dilakukan dengan baik, kemudian dilanjutkan dengan melakukan pengujian kecepatan respon antara mobil robot dengan gestur tangan. Pengujian ini dapat dilihat pada Tabel 3. di bawah ini:

Tabel 3. Hasil Uji Respon Sensor

\begin{tabular}{|c|c|c|c|c|c|}
\hline Code & Test 1 (s) & Test 2 (s) & Test 3(s) & Test 4 (s) & Mean (s) \\
\hline Forward & 0.45 & 0.44 & 0.45 & 0.45 & 0.45 \\
\hline Backward & 0.43 & 0.44 & 0.44 & 0.44 & 0.44 \\
\hline Left & 0.44 & 0.44 & 0.44 & 0.44 & 0.44 \\
\hline Right & 0.45 & 0.44 & 0.45 & 0.45 & 0.45 \\
\hline Stop & 0.45 & 0.45 & 0.45 & 0.45 & 0.45 \\
\hline
\end{tabular}

Dari Tabel 3. di atas terdapat nilai rata - rata dari setiap kode instruksi maju, mundur, kiri, kanan, dan berhenti sebanyak $0,45 \mathrm{~s} ; 0,44 \mathrm{~s} ; 0,44 \mathrm{~s} ; 0,45 \mathrm{~s} ; 0,45 \mathrm{~s}$.

Pengujian berikutnya meliputi tentang uji jarak koneksi respon antara mobil robot dengan gestur tangan. Pengujian ini dapat dilihat pada diagram Gambar 8. di bawah ini: 


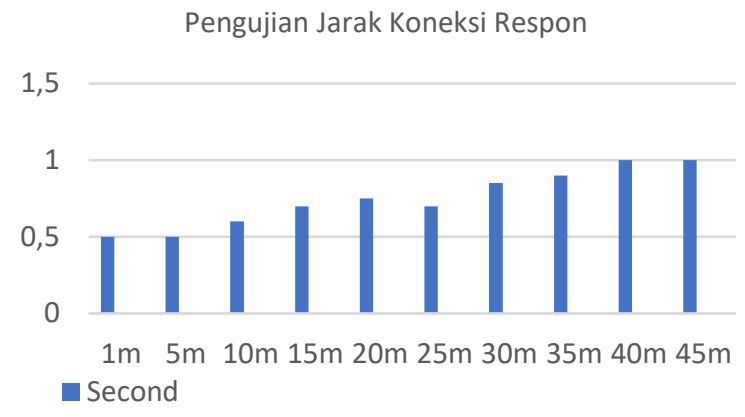

Gambar 8. Diagram Pengujian Jarak Koneksi Respon Mobil Robot - Gestur Tangan

Pengujian pada tertera pada Gambar 8. di atas menjelaskan bahwa ketika gestur tangan dengan mobil robot berjarak 1 meter, kecepatan koneksi responnya hanya membutuhkan waktu 0,4s. Sedangkan, kecepatan koneksi respon sensor gestur tangan dengan mobil robot yang berjarak $45 \mathrm{~m}$ itu membutuhkan waktu selama 1s. Dengan demikian, diantara kedua jarak tersebut terjadi selisih sebanyak $0,6 \mathrm{~s}$.

Untuk melengkapi data penelitian ini, dilakukan pengujian akselerasi kecepatan mobil robot yang dijalankan dengan berbagai macam kondisi jalan. Hasil pengujian terlihat seperti pada Tabel 4. dilakukan di tempat jalan yang datar, menukik, maupun jalan yang menanjak.

Tabel 4. Hasil Uji Akselerasi Kecepatan Mobil Robot

\begin{tabular}{|c|c|c|c|c|c|}
\hline $\begin{array}{c}\text { Condition } \\
\text { Road }\end{array}$ & $\begin{array}{c}\text { Test 1 } \\
(\mathrm{rpm})\end{array}$ & $\begin{array}{c}\text { Test 2 } \\
(\mathrm{rpm})\end{array}$ & $\begin{array}{c}\text { Test 3 } \\
(\mathrm{rpm})\end{array}$ & $\begin{array}{c}\text { Test 4 } \\
(\mathrm{rpm})\end{array}$ & $\begin{array}{c}\text { Mean } \\
(\mathrm{rpm})\end{array}$ \\
\hline Flat & 3970 & 4137 & 4035 & 4213 & 4088.75 \\
\hline Downhil & 4538 & 4552 & 4691 & 4605 & 4596.50 \\
\hline Uphill & 3502 & 3448 & 3489 & 3439 & 3496.50 \\
\hline
\end{tabular}

Terlihat pada Tabel 4. di atas menunjukkan bahwa rata-rata kecepatan mobil robot saat bergerak di jalan mendatar sebesar 4.088,75 rpm. Ketika mobil tersebut bergerak di jalan yang menurun atau menukik rata-rata kecepatannya bertambah menjadi 4.596,50 rpm. Sedangkan saat mobil robot tersebut digerakan di jalan yang menanjak kecepatan rata-ratanya menurun menjadi $3.496,50 \mathrm{rpm}$.

\section{KESIMPULAN}

Hasil pengujian yang telah dilakukan membuktikan bahwa kendali mobil robot ini mampu bekerja maksimal dengan menggunakan isyarat tangan manusia. Pembacaan gestur tangan dengan menggunakan modul sensor MPU-6050 mampu membaca posisi titik sumbu $\mathrm{x}$, y, dan $\mathrm{z}$ yang dijadikan sebagai input perintah logika pemrograman untuk menentukan aksi berupa gerakan arah mobil robot. Penggunaan antena NRF24L01 sebagai media transmisi berupa gelombang frekuensi juga dianggap mampu berfungsi dengan baik dan efisien di dalam sistem elektrik mobil robot.

Selain itu, hasil respon sensor terhadap mobil robot mampu terhubung cepat hanya dengan selang waktu $0,44 \mathrm{~s}-0,45 \mathrm{~s}$ dan mampu bergerak normal sejauh $45 \mathrm{~m}$ di dalam pengujian tersebut. Rata-rata kecepatan mobil robot tersebut mampu melaju sebesar 3.496,50 rpm sampai dengan 4.596,50 rpm dengan berbagai kondisi jalan yang dilalui. 


\section{DAFTAR PUSTAKA}

[1] Kim, H., dan Felner, D.W., 2004, "Interaction with hand gesture for a back projection wall", CGI '04: Computer Graphics International.

[2] A. A. Alani and G. Cosma. 2018. Hand Gesture Recognition Using an Adapted Convolutional Neural Network with Data Augmentation,\| 2018 4th Int. Conf. Inf. Manag., pp. 5-12.

[3] S. Hussain and R. Saxena.2018. Hand Gesture Recognition Using Deep Learning,॥ pp. 48-49.

[4] A. . Arvindan and K. D.2016. "Experimental Investigation of Remote Control Via Android Smart Phone of Arduino-Based Automated Irrigation System Using Moisture Sensor," pp. $168-175$.

[5] Y. Hendriana and R. Hardi.2016. "Remote Control System as Serial Communications Mobile using a Microcontroller,". pp19-25.

[6] J. P. Ventura, N. A. Cruz, and F. P. Lima, 2016. "A remote monitoring and control system for ecosystem replication experiments,".

[7] Y. Curiel-razo and O. Icasio-hern.2016. "Leap Motion Controller Three Dimensional Verification and Polynomial Correction," Measurement.

[8] R. Katahira and M. Soga.2015. "Development and Evaluation of a System for AR enabling Realistic Display of Gripping Motions using Leap Motion Controller," Procedia - Procedia Comput. Sci., vol. 60, pp. 1595-1603.

[9] K. Fok, N. Ganganath, C. Cheng, and C. K. Tse,2015. "A Real-Time ASL Recognition System Using Leap Sensors,". 